\title{
A gestão situacional (em saúde) e a organização comunicante
}

\author{
Situational management (in health) and \\ communicative organization
}

Francisco Javier Uribe Rivera 1

1 Escola Nacional de Saúde Pública, Fundação Oswaldo Cruz.

Rua Leopoldo Bulhões, 1480, Rio de Janeiro, RJ, 21041-210, Brasil.
Abstract In this paper, the organizational theory of situational planning is used to establish a decentralized management model for complex health units. Because of cultural limitations imposed on a perspective of change and rationalization, considerations are made in relation to a given form of dealing with culture, keeping in mind the feasibility of the management model. A particular type of communicative management emerges as a general need reveal ed by the analysis of the object at issue: the management of professional organizations.

Key words Situational Management; Communication and Management; Decentralization; Health Planning

Resumo Neste trabalho, a teoria organizacional do planejamento situacional é utilizada na fundamentação de um model o descentralizado de gestão de uni dades complexas de saúde. Dadas as limitações culturais a uma perspectiva de mudança e de racional ização, consi derações são feitas a respeito de uma determinada forma de se trabalhar a cultura, tendo em vista a viabilização do projeto de gestão. Um tipo particular de gerência comunicativa surge como necessidade geral col ocada pela análise do objeto em questão: a gestão de organizações de ti po profissi onal . Palavras-chave Gestão Situacional; Comunicação e Gerência; Descentralização; Planejamento em Saúde 


\section{Introdução}

O motivo central deste trabalho é analisar a lógica da teoria macroorganizacional do Planejamento Estratégico-Situacional (PES), na medida em que a mesma pode informar uma dada estratégia de desenvolvimento de uma organização comunicante. Assumimos este tipo de organização como um modelo ideal para organizações profissionais de saúde, considerando algumas características particulares de seus processos de trabal ho e de sua estrutura de poder. A análise, que aqui fazemos, do desenvolvimento de formas de gestão descentralizada de estabelecimentos sanitários insere-se no âmbito empírico-organizativo de uma investigação mais ampla, voltada para a afirmação de um enfoque lingüístico ou comunicativo da gestão em geral.

Neste trabalho, procuramos, todavia, fazer uma primei ra aproximação ao conceito de cultura institucional, fenômeno que define, em última análise, as possibilidades de atuação transformadora sobre uma organização. A constituição de um tipo de organização racionalizada implica o desafio crucial de ter que se ver com a questão da cultura. O como agir visando a enfrentar uma dada cultura resistente à mudança estará aqui implícito. A necessidade de definir melhor essa abordagem suscita o início de uma problematização que esperamos sistematizar no futuro, na perspectiva de dispormos de novos instrumentos de trabalho para uma modelagem transformadora.

Acreditamos que com estas linhas contribuiremos para a realização de uma atualização dos conteúdos do momento tático-operacional do PES, que concernem particularmente à implantação de um modelo de direção ou de gestão, e para polemizar com aquelas correntes que sustentam que esse modelo é instrumental ou muito diretivo. Uma determinada leitura, que busca captar elementos de um paradigma comunicativo no interior dessa proposta, reposiciona essa construção, imunizando-a contra críticas ligeiras. Os vazios de construção são também apontados - como é a questão do trabalho com cultura - no intuito de definir uma perspectiva mais abrangente de intervenção no campo da racionalização gerencial.
Estratégia de desenvolvimento de uma organização comunicativa

A modelagem organizacional ou intervenção com vistas à mudança supõe sempre uma situação-objetivo ou um modelo ideal de organização.

Para Carlos Matus, ideólogo do PES, o modelo de uma organização racional corresponde, na nossa interpretação, a uma organização planejada, criativa, participativa e responsável.

Para Bartoli (1992), essa situação-objetivo se identifica com o formato "de uma organização comunicante de comunicação organizada".

A organização que se pretende comunicante deve apresentar determinadas características:

- Aberta, para se comunicar com o exterior (meio), em emissão e recepção interativas.

- Evolutiva, quer dizer, nem rotineira nem excessi vamente formalista para manejar a evolução e o imprevisto.

- Flexível, para permitir uma dose oportuna entre comunicação formal e informal.

- Com finalidade explícita, para proporcionar um fio condutor para a comunicação formal.

- Responsabilizante para todos, a fim de evitar a busca de um poder artificial por parte de alguns mediante a retenção de informação.

Uma organização comunicante deve apoiarse em uma comunicação organizada, dada a inseparabilidade entre comunicação e organização. A comunicação deve apresentar, nesta perspectiva, algumas características:

- Deve ter uma finalidade, ou seja, deve estar vinculada a objetivos e a um plano de conjunto. - Deve ser multidirecional, isto é, de cima para baixo, de baixo para cima, transversal, interna-externa.

- Deve estar instrumentada e utilizar-se de ferramentas, suportes, dispositivos, indicadores selecionados em função dos objetivos.

- Deve estar adaptada, integrando sistemas de informação administráveis, administrados e adaptados às necessidades específicas de cada setor levando sempre em conta a cultura do meio.

- Deve ser flexível, para integrar o informal e criar estruturas que o favoreçam.

Como antecipamos, uma análise das características das organizações sanitárias, considerando a tipologia organizacional de Mitzberg, sugere uma forma de gestão setorial baseada na negociação e comunicação intensivas, em formas flexíveis e descentralizadas de estrutura, no desempenho de colegiados de gestão como lugares de consenso e em uma autonomia 
importante para os centros operadores. Esta questão será analisada com maior profundidade mais adiante. Queremos aqui apenas frisar que as características desse enfoque de gestão tendem a coincidir com os atributos de uma organização comunicante (que não se diferenciam significativamente das características da organização racional matusiana).

A questão que se coloca aqui é a de criar uma estratégia que permita pensar o alcance dessa situação-objetivo. Exploraremos o PES.

Para a Teoria Macroorganizacional de Matus (1994a), os componentes básicos (regras) de uma organização são quatro:

- A direcionalidade, que corresponde à missão, às funções de uma organização.

- A departamentalização, que equivale à transformação da direcionalidade em formas organizativas específicas, constituídas por sistemas de produção terminal e intermediária que se relacionam em uma determinada rede, com mecanismos de coordenação e de comunicação definidos.

- A governabilidade, que expressa a distribuição do poder administrativo (recursos críticos necessários ao exercício das funções atribuídas às unidades de produção) e das competências dos vários níveis organizativos.

- A responsabilidade, que explicita a forma como são atribuídas ou distribuídas as responsabilidades, e o modo como as mesmas são cobradas.

Tudo indica que a existência de uma forte vinculação entre as primeiras regras (sugerindo uma inseparabilidade) leva Matus a limitarse a trabal har conclusivamente com as regras de direcionalidade, de governabilidade e de responsabilidade. Estas regras traduzir-se-iam em determinados sistemas ou acumulações organizativos. A direcionalidade se expressaria no sistema de agenda e nas estruturas organizativas. A governabilidade o faria através do sistema de competências internas, do sistema de regulação e de alocação de recursos, dos sistemas de coordenação e de informação/ comunicação, das instâncias de governo em cada nível, das metodologias e formas de gestão, enfim daquilo que Matus engloba no(s) sistema(s) de gerência. A responsabilidade encarnaria no sistema de petição e prestação de contas e na cultura organizativa que lhe é pertinente.

As relações existentes entre estas regras são, para Matus, de mútuo condicionamento, predominando em última instância a responsabilidade (regra decisiva)

De acordo com a direcionalidade, as organizações poderiam ser adequadas ou inadequadas, dependendo de a oferta institucional se ajustar ou não a uma demanda social. Segundo a governabilidade, as organizações poderiam ser centralizadas ou descentralizadas, refletindo a relação entre o valor dos problemas e a competência para enfrentá-los (nas organizações centralizadas os níveis periféricos não teriam a competência e o acesso aos recursos críticos necessários ao enfrentamento de problemas de alto valor que se apresentam). E de acordo com a responsabilidade, as organizações poderiam ser de baixa ou alta responsabilidade, em função da clareza e organicidade da atribuição e cobrança de responsabilidades.

A qualidade da gestão, para esse autor, depende da natureza do jogo organizativo, definido pela situação das regras básicas.

O funcionamento destas regras configura um determinado "triângulo de ferro" ideal ou negativo, caracterizado por um determinado tipo de formato assumido pela interação agenda/ sistema de gerência, sistema de prestação de contas as traduções finalísticas da direcionalidade, da governabilidade e da responsabilidade, respectivamente.

Em um sentido ideal, a petição de contas por problemas e resultados (primariamente da ambiência externa) cria a necessidade de uma planificação sistemática no escritório do dirigente máximo e isto contribui para uma racionalização de sua agenda, que destaca os problemas importantes. Cria-se, assim, uma demanda geral por planificação nos organismos públicos, que abre a oportunidade da gerência (descentralizada) por operações como processo criativo. A gerência por operações cria a possibilidade prática da planificação descentralizada e a possibilidade de prestar contas por problemas e resultados. A petição e prestação de contas motiva uma melhor qualidade da agenda, da planificação, da gerência etc.

Aqui, é importante destacar que a racionalização da agenda do dirigente é um estímulo indireto para a descentralização de problemas não necessariamente classificados como de alto valor para essa agenda. Por outro lado, é necessário precisar que Matus concebe a planificação como inseparável da gestão (esta última corresponderia à condução na conjuntura orientada por um plano estratégico ou ao momento tático-operacional do PES). Desta maneira, a demanda por um determinado tipo de planejamento caracterizado pela criatividade pode significar a transmissão dessa característica ao sistema de gestão, pois este transformaria - na concepção matusiana - os módulos do plano em módulos de gerência. Criatividade é um termo-chave no autor. Ele denota o processamento intensivo de problemas em uma rede 
de comunicação motivada e motivadora, um processo sistemático (articulando vários critérios de cálculo), totalizador e rigoroso. Conota, ainda, a definição/ ou processamento de macrounidades de ação que enfrentarão esses problemas dentro de um desenho não rígido (as operações) e uma preocupação com a adequação estratégica do plano por operações e com a criação de dispositivos de gestão que o viabilizem organizativamente. Este tipo de processamento criativo é função, para o autor, de estar enfrentando problemas de alto valor (importantes para o cumprimento de funções) e quase-estruturados (de variáveis não completamente conhecidas ou consensuais). A arte de dirigir, como se verá mais adiante, depende de sempre distribuir para todos os níveis problemas de alto valor ou distribuir as capacidades de enfrentamento dos mesmos. Isto suscitaria a necessidade de um tratamento não rotineiro. Criatividade e descentralização assim se confundem. Por fim, não haveria, para o autor, problemas completamente óbvios que dispensassem a criatividade, uma espécie de pulsão elaborativa de transformação.

Em um sentido negativo, a baixa responsabilidade (traduzida por mecanismos frouxos de atribuição e de cobrança de responsabilidades) gera um triângulo de ferro que opera da seguinte maneira:

- Não há um sistema operativo de solicitação e de prestação de contas (predomina a irresponsabilidade);

- não há uma conformação racional da agenda (nesta predominam a improvisação, as rotinas e emergências);

- o sistema de gerência é tradicional, ou seja, este sistema não está voltado para o processamento de problemas e operações, para a análise, implementação e monitoramento de produtos e resultados prioritários, mas circunscrito ao controle de cumprimento de rotinas processuais.

O triângulo de ferro é um instrumento conceitual que pretende dar conta das relações que se estabeleceriam entre os principais sistemas organizativos, reforçando sua mútua dependência, e que possibilita pensar a intervenção sobre uma organização no sentido transformador.

Preocupados com este aspecto da extrema vinculação existente entre todas as regras organizacionais, gostaríamos de apontar aqui algumas ilustrações:

- A departamentalização específica depende da missão, a qual define as tecnologias ou formas de realização (organização) do trabalho, que condicionam a estrutura organizativa;
- uma indefinição da missão implica a impossibilidade de definir as competências internas, o que se traduz em ingovernabilidade;

- a cobrança social estimula ou permite a adequação da missão, mas a missão determina o que vai ser objeto de cobrança internamente; - a cobrança social gera o tipo de circuito relatado, pertinente à dinâmica positiva do triângulo de ferro (redundando, por exemplo, em uma gerência descentralizada);

- uma maior governabilidade (traduzida pela descentralização) facilita a avaliação de responsabilidades;

- uma baixa responsabilidade pode anular uma missão claramente definida ou o exercício de um sistema de competências que aponte para a descentralização.

É difícil depreender desta malha de relações as regras mais importantes. As consi derações anteriores apontam para a missão e a responsabilidade como determinantes básicos. Matus, extremamente preocupado em explicar as insuficiências do planejamento, opta por priorizar a responsabilidade, que estabeleceria, em última instância, o grau de adequação da missão e uma determinada demanda por racionalização gerencial.

Afirmamos acima que a lógica do triângulo de ferro ajuda a pensar a mudança. Neste sentido, a estratégia globalista de transformação preconizada pelo PES, de atacar simultaneamente todas as regras no contexto de uma reforma administrativa vertical, é a resultante natural da compreensão das inter-relações que caracterizam o funcionamento daquelas. Esta reforma administrativa se opõe à reforma horizontal, definida pela tentativa de reforma de um único sistema. Matus afirma que, dada a mútua suposição dos sistemas, a mudança em um único sistema organizativo tende a retroagir ao estado anterior de estabilidade medíocre, implicando apenas dados de fachada ou significando a introdução de sistemas meramente ritualísticos.

Esta estratégia globalista é confirmada por Bartoli (1992), preocupada basicamente com a introdução de um plano de comunicação. A inseparabilidade dos termos comunicação e organização e a dependência de ambos de uma estratégia política global e das características sócio-culturais da organização (poder e sistemas de idéias e valores) sugerem um projeto abrangente que equacione todos estes aspectos coordenadamente. Como a autora afirma: “La acción combinada sobre organización y comunicación apunta a obtener efectos positivos en el plano económico y en el social. Un objetivo de esa naturaleza puede traducirse me- 
diante elecciones explícitas de estratégia interna plasmadas en planos de acción, mediante la mejora de los comportamientos de los principales comunicadores (los cuadros superiores especialmente), mediante la restructuración de sectores de trabajo para facilitar la concertación y la creación de dispositivos de intercambio (grupos de trabajo) y mediante la búsqueda de un mínimo de cohesión cultural para sentar la viabilidad de la gestión en la implicación de la mayor cantidad de actores posible" (pág. 202).

A estratégia de reforma administrativa do PES implica a criação de um sistema de direção estratégica ou de gestão, constituído por vários subsistemas articulados em torno das três pontas do triângulo:

- O sistema de solicitação e de prestação de contas articula um sistema de monitoramento estratégico;

- o sistema de gerência descentralizado articula um sistema de planejamento ad-hoc e um sistema de orçamento-programa;

- o sistema de agenda articula uma unidade de processamento técnico-político (UPTC), ligada na cúpula ao processamento de problemas do sistema de planejamento em geral.

A estratégia de implantação desse sistema geral supõe uma seqüência geral, qual seja: 1) a necessidade de um centro de treinamento, enquanto um sistema básico capaz de propiciar a introdução das práticas e sistemas referidos, através da modificação das estruturas mentais; 2) a introdução da lógica do planejamento por problemas e, simultaneamente, da conformação racional da agenda. Uma outra onda transformadora suporia 3) o desenvolvimento do sistema de monitoramento e 4) o desenvolvimento do sistema de prestação de contas, estes últimos baseados nos dados do plano por problemas. Finalmente, seria enfrentada 5) a transformação das formas organizativas.

A nossa preocupação agora passa a ser ajudar a precisar as diretrizes e características do sistema de gerência descentralizado, que se confunde, segundo nosso ponto de vista, com um tipo de estratégia ou de gestão voltada para o desenvolvimento de uma organização comunicante.

Três princípios de organização do PES podem nos ajudar nesta tarefa: o princípio da responsabilidade, o princípio da descentralização e o princípio da subordinação das formas organizativas às práticas de trabal ho e destas às estruturas mentais.

O princípio da responsabilidade estabelece que “uma instituição está sujeita a regras de alta responsabilidade se nela ninguém está isen- to de prestar e pedir contas de forma sistemática sobre seu desempenho real em relação aos compromissos assumidos" (M atus, 1994, trad. nossa). Este princípio determina que, sem responsabilidade, não há planificação, sugerindo que o processo de planejamento se estabelece quando os dirigentes e trabalhadores são submetidos a algum tipo de cobrança sistemática. Sem a pressão da cobrança, não haveria estímulo para a planificação. A definição inicial deixa transparecer, por outro lado, que a prestação de contas se estabelece sobre compromissos assumidos, dando lugar à interpretação de que a prestação de contas supõe a plena participação no processo de adoção de compromissos por parte do sujeito-objeto da cobrança (e a constatação de que entre planejamento e prestação de contas existe uma relação circular). Veremos a seguir que a adoção de compromissos com base no processamento de problemas, nos moldes do PES, é um processo orientado pela busca da criatividade inerente ao princípio da descentralização.

Este segundo princípio da descentralização reza o seguinte: “Ningun problema cuasiestructurado debe ser procesado en un nível en que reciba un tratamiento rutinario, todo problema debe ser procesado creativamente. Si un problema recibe un trato rutinario porque tiene bajo valor en ese nível, debe descender en la estructura macroorganizativa hasta el nível descentralizado en que tenga alto valor y pueda ser tratado creativamente. Todo problema debe ser enfrentado en aquel nível en que tiene alto valor. Cada nível jerárquico organizativo debe tener gobernabilidad sobre los problemas de alto valor que lo afectan, salvo el caso de los problemas que puden disolverse eficazmente en un espacio mayor". A complementação deste princípio, em relação aos problemas bem estruturados, é o seguinte: “Todo problema bien estructurado debe descentralizarse mediante normatización" (Matus, 1994a).

O confronto destes dois princípios permite concluir que, sem responsabilidade, não há planificação e que, sem planificação, não há disciplina criativa. Neste sentido, a outra face do princípio da responsabilidade é a criatividade. Matus, na obra citada, afirma que "a responsabilidade obriga à criatividade e a criatividade obriga à descentralização". O manejo descentralizado de informação e a participação no processo decisório fazem parte daquelas condições básicas de uma organização responsabilizante para todos que evita monopólios de poder.

O segundo princípio mencionado precisa ser complementado com definições sobre a es- 
trutura de poder e sobre as características do sistema de gerência por operações, de modo a se ter uma visão mais precisa das bases do modelo matusiano de gestão.

Na parte referente às regras de governabilidade da Teoria das Macoorganizações, Matus (I994a) sustenta: “El poder concentrado mata la creatividad y la capacidad de respuesta oportuna del sistema ante los cambios de la realidad y las oportunidades. El poder concentrado enfatiza las relaciones jerárquicas de dependencia, mientras que la distribución del poder enfatiza las relaciones de coordinacion. A su vez, el poder concentrado acumula en la cúspide innumerables problemas de bajo valor en ese nível, pero de alto valor en la base. En cambio, el poder bien distribuído permite que, en cada nivel organizativo, sólo se trabaje con problemas de alto valor. La importancia de esto es óbvia, pues la velocidad y la criatividad en el enfrentamiento de los problemas depende del valor que ellos tienen para qien tiene el poder de resolverlos".

No Guia Teórico do PES, Matus (I994b) define as funções e as características do Sistema de Gerência por Operações. Este sistema objetivaria "descentralizar o cumprimento das missões, criando espaços institucionais de autonomia circunscrita às diretrizes superiores do sistema de direção. Dentro deste espaço a gerência por operações tem plena liberdade para desenvolver sua criatividade a serviço do cumprimento da missão recebida". As características do sistema seriam as seguintes:

- É um sistema particular de gerência por produtos e resultados (gerência por objetivos) que assume os módulos do plano por problemas como módulos de gerência e que exige a avaliação por resultados.

- Está articulado a um Orçamento-programa. - Permite a prestação de contas por problemas, por operações e por resultados dessas operações.

- Exige como suporte um sistema de informação (monitoramento) por problemas e operações.

- É um sistema descentralizado.

Propõe-se, por conseguinte, um modelo de gestão criativo (ou articulado a um planejamento estratégico por problemas) baseado em estruturas flexíveis, descentralizadas, intensivas em comunicação vertical e, prioritariamente, em comunicação horizontal, lateral . Este modelo estaria indissoluvelmente ligado à responsabilização.

É importante esclarecer que esse sistema de gerência assume como produtos as metas das operações voltadas para determinados problemas (em um recorte seletivo). Neste sentido, ele é a dimensão de matricialidade de um sistema mais amplo de gerência por produtos, em que estes se confundem com as missões assinadas. De acordo com este entendimento, os gerentes de projetos ou de operações podem contribuir para integrar várias unidades de trabalho definidas por produtos homogêneos, tendo em vista que os problemas das operações podem atravessar aquelas. Os problemas a que as operações visam definem-se como obstáculos ao cumprimento de uma missão ou de um conjunto. Nesta medida, a gerência por problemas se confunde com o gerenciamento da produção terminal, sobre a qual estaria concentrada a dinâmica PES.

O terceiro princípio fundamental da Teoria das Macroorganizações é o da subordinação das formas organizativas às práticas de trabaIho e destas, por sua vez, às estruturas mentais.

$M$ atus afirma que as formas organizativas podem ser mudadas formalmente sem que isto importe em modificações das práticas de trabalho e vice-versa, sendo que o mais importante é a qual idade das práticas de trabal ho, concebidas como as formas de realização dos processos de produção intermediária e terminal, os microprocessos administrativos e as conversações organizativas (os componentes básicos da organização do ponto de vista dos fluxos de produção social).

O autor referido sustenta que uma macroadequação organizacional implica prioritariamente pensar os produtos organizacionais, a rede de produção institucional. As formas organizativas devem adaptar-se ao desenho da rede de produção, elas são formas condicionadas por esse desenho. Assim, no texto El Método PES, Reingenieria Pública y la Teoria de Las Conversaciones, Matus (I994C) dirá: “Una vez que el proceso está rediseñado y son claras sus prácticas de trabajo, la forma de la estructura organizativa es evidente... Las prácticas de trabajo que caracterizan cada processo determinan el organigrama más eficaz y no a la inversa".

Pensando basicamente na modificação das práticas de trabalho ligadas à produção intermediária: direção e planejamento, Matus sustenta em sua Teoria Macroorganizativa que as estruturas mentais (que condicionam uma gerência tradicional) podem ser mudadas através da teoria e do treinamento e que as práticas de trabalho específicas podem mudar através da introdução dos sistemas de direção já referidos prévio treinamento.

Duas exigências são colocadas por este princípio: a) a de pensar a organização em ter- 
mos dos seus produtos e da responsabilidade pelos mesmos; b) a de organizar uma estratégia de treinamento formal e informal que, adscrita às práticas de trabal ho e tendo um caráter permanente, possa influenciar decisivamente as estruturas mentais (concebidas como cultura institucional).

A análise conjugada e dinâmica desses três princípios põe em evidência o sentido comunicativo da proposta matusiana. A centralidade assumida na proposta de uma gerência descentralizada por uma sistemática de planejamento estratégico concebida como um lugar de problematização em grupos de trabalho representativos (policêntricos) define os espaços de comunicação basilares. As palavras-chave aqui são o "processamento sistemático de problemas e soluções" e o "processamento criativo em grupo".

Em segundo lugar, a idéia de uma responsabilização para todos implica, além da clara assunção de compromissos gerados participativamente, um tipo de monitoramento que se baseia em algumas características básicas definidas pelo Manual Altadir de Monitoramento (Matus, 1994d). Este sistema de informação teria que ser:

- Em tempo eficaz, para não marchar a reboque dos fatos e permitir a retroalimentação da ação;

- seletivo, no sentido de conter especificamente os dados necessários ao plano de ação;

- de fluxo horizontal, no sentido de configurar um processo onde a informação é produzida descentralizadamente, visando a um usuário específico do nível respectivo etc.

Estas características correspondem, para nós, a um entendimento da informação como comunicação. Nesta acepção, o sistema de informação seria uma fonte de diálogo e um estímulo para a ação. O fluxo de informações estaria articulado a um processo de comunicação que, diferentemente da simples transmissão unidirecional de dados sobre fatos, representaria uma interação ou intercâmbio de informação, onde o emissor seria também receptor e vice-versa na mesma seqüência de comunicação, e onde o objetivo seria a mudança do comportamento dos outros ou a mudança da ação. O "mudar o comportamento dos outros" alude ao processo de influência que gera decisões corretivas ou novas decisões envolvendo pessoas e processos.

Como diz Bartoli (1992): "el indicador de control debe ser pensado de manera convencional entre los actores, pues no existe un buen indicador absoluto. Lo esencial es que responda a un lenguaje común de análisis y acción...
El análisis de los indicadores de control se referirá, entonces, a su existencia, al grado de participación en su elaboración, a la claridad de los objetivos de cada indicador, a la práctica de actualización de los mismos y a la comprensión y utilización por parte de los usuários de las indicaciones obtenidas". Esta dimensão consensuada dos indicadores de controle e seu caráter seletivo e prático (no sentido da ação) inscreve-se necessariamente em uma estratégia de comunicação organizacional.

O terceiro princípio acima mencionado traz à tona a questão de se trabalhar com cultura como possibilidade de mudança ou restrição à mesma. A definição de cultura de Matus enquanto estruturas mentais é insuficiente. Da mesma forma, a estratégia de desenvolvimento teórico e de treinamento, embora seja fundamental, não esgota as possibilidades de atuação sobre a cultura. Adiante faremos al guns comentários sobre tão importante assunto, no intuito de procurar preencher essa lacuna e de lançar uma provocação para nós mesmos assumirmos o desafio de palmilhar esse caminho analítico futuramente; apenas avançamos que a comunicação - enquanto prolongamento necessário da cultura - é o meio privilegiado de conformação da mesma. Daí a necessidade de um plano de comunicação que impacte a cultura.

A questão do correto esclarecimento dos produtos organizacionais, por outro lado, chama a atenção para a necessidade de uma boa declaração da missão e papéis derivados. Autores como Covey (1994) realçam a importância de uma declaração de missão que envolva todos os níveis organizacionais e que opere como uma verdadeira constituição institucional. Esta definição não deveria ser improvisada ou forjada pela direção, mas construída participativamente em verdadeiras jornadas de discussão e delimitação da mesma, consi derando vários critérios, não apenas os exclusivamente econômicos. Esta declaração trabalharia decisivamente na direção de uma maior motivação ou adesão e da coordenação intrainstitucional.

Recentemente, o PES decidiu abraçar a teoria das conversações de Fernando Flores e elementos do que Matus (1994c) denomina uma Reengenharia Pública. Procede analisar de modo conciso em que medida estas contribuições permitem alimentar uma estratégia de gestão comunicativa.

Flores, em sua tese de doutoramento: “A Empresa do Século XXI" (1989), assenta uma nova interpretação das organizações enquanto eventos lingüísticos. Seu marco referencial é duplo: de um lado, a filosofia analítica da lin- 
guagem de Austin e Searle Ihe ajuda a entender a organização como uma rede recorrente de conversações onde predominam os atos diretivos (petições) e os atos comissivos ou os compromissos; de um outro lado a hermenêutica heideggeriana Ihe fornece a idéia de mundo organizacional ou tradição enquanto estrutura que pré-determina os compromissos. Neste particular, o autor destaca o papel sobredeterminante da cultura. A aplicação prática imediata desta compreensão lingüística é um programa denominado o Coordenador, um administrador de conversações. Assentado na premissa de que o conjunto de possibilidades de conversações organizacionais é uma rede finita, este instrumento computacional objetiva racionalizar o processo de geração lingüística de compromissos, possibilitando a interação comunicativa a distância das pessoas envolvidas naquele. É, por outro lado, um instrumento de monitoramento desses compromissos. Uma análise mais profunda desta contribuição será feita em outros trabalhos.

Sobre este instrumento, Matus comenta: “El administrador de conversaciones es también una revolución en la teoria de la organización y, en su breve práctica, ha demostrado su potencia para cambiar la cultura institucional. Esta revolución está comenzando y, gracias a la comunicación por la via inteligente de las computadoras, es posible que se derriben barreras jerárquicas y departamentales. Un administrador de conversaciones reduce al minimo el contacto físico, obliga a una gran precisión y brevedad en las conversaciones, hace transparente el incumplimiento de los compromissos, rastrea automáticamente el cumplimiento de las directivas, democratiza la organización jerárquica, que hace a los funcionários participantes de una red de conversaciones igualitária" (1994c).

Flores reforça a idéia de que este administrador é um instrumento de educação, na medida em que adestra no imperativo de assumir compromissos e traz à tona o caráter social da ação, pois registra a rede interativa que medeia uma ação enquanto um evento precedido de atos comunicativos.

Da Reengenharia, Matus se apropria de várias premissas:

- A necessidade da compactação de processos, reunindo as tarefas ou etapas de um mesmo processo em uma mesma unidade organizativa, de modo a reduzir o tempo morto entre as tarefas, aumentar a responsabilização pelo produto desse processo e possibilitar o desenvolvimento de equipes de processos.

- A necessidade de um único contato externo (com o cliente) vis-a-vis múltiplos pontos de contato.

- A idéia de um controle simples e global por oposição à saturação de controles.

- A idéia de combinar de maneira inteligente a central ização e a descentral ização, só possível pela tecnologia de informação enquanto capacitadora da reengenharia.

- A idéia de saber combinar a padronização de processos com a diferenciação dos mesmos.

A premissa da diferenciação é uma idéia importante para a Reengenharia. Para Hammer \& Champy (1994), no mundo de hoje de produtos cada vez mais individualizados, a padronização rígi da é uma premissa ultrapassada, sendo cada vez mais necessário um tipo de produção caracterizado pela diversidade criativa de processos.

Algumas dessas premissas reforçam a estratégia de comunicação que trabalhamos. Claramente, o princípio da compactação de processos aponta para equipes criativas de processos onde a comunicação horizontal é intensa e imprescindível. O princípio de um único contato externo se correlaciona com a proposta de trabalhadores de caso ou generalistas que respondem a várias exigências do cliente, em uma interação comunicativa. O princípio da diversificação tem a ver com a necessidade de um contato cada vez mais individual izado com o ambiente, o qual deve ser realçado quando esse ambiente é constituído por clientes que travam uma interação produtiva e comunicativa com os trabalhadores (caso das organizações profissionais, como as sanitárias e de educação).

Em vários momentos, afirmamos que, dadas as características das organizações de saúde, o modelo ideal de gestão das mesmas aproxima-se de uma organização comunicante. Que características são essas? Como encarar sua gestão específica?

Autores como Rivera (1995a; 1995b) e Lemos (1994) procuram sistematizar alguns traços distintivos das chamadas organizações profissionais de saúde (aludindo à denominação de Mitzberg):

- O poder nestas organizações está distribuído; ninguém concentra todo o poder.

- Os processos de trabalho são coordenados com base no conhecimento especializado adquirido pelos profissionais de saúde, especialmente os médicos, fora do sistema.

- Esses processos são extremamente diversificados, apresentam relações de insumo-produto instáveis ou variadas, envolvem vários setores e geram produtos e resultados de difícil precisão.

- O corporativismo profissional dificulta a di- 
nâmica de equipe de saúde, tão necessária a essas organizações.

- Em geral, as nossas organizações têm uma governabilidade relativa, pois dependem significativamente da negociação de recursos controlados pelos níveis superiores da administração pública.

- As atividades terminais envolvem relações produtivas inseparáveis de uma relação interativa e comunicacional com os clientes, os quais participam ativamente quase que como co-responsáveis pelo trabalho.

As exigências implícitas nesse quadro apontam para um enfoque de gestão onde:

- É necessário estabelecer ativamente formas de comunicação e de coordenação do trabalho de vários setores e profissionais, assim como negociar o esquema de poder;

- a padronização mecanística não tem lugar, justificando-se uma autonormatização dos centros operadores baseada em uma disponibilidade de autonomia importante e uma integração entre trabalho assistencial e gerencial;

- é necessário negociar critérios de avaliação de eficácia e eficiência, de modo a garantir uma responsabilização consciente, que contrabalance eventuais efeitos deletéreos de uma autonomia exagerada;

- os critérios de bom atendimento dos clientes precisam ser considerados como elementos importantes de definição de metas, padrões e diretrizes de atendimento;

- o raciocínio estratégico de barganha de recursos em um ambiente fortemente político é um imperativo que torna o planejamento meramente normativo algo extremamente insuficiente etc.

Uma gestão comunicativa que leve em conta variáveis estratégicas de poder é uma alternativa necessária a modelos tradicionais de planejamento/ programação de serviços e de gestão rotineira.

Como pensar especificamente o modelo gerencial de estabelecimentos complexos de saúde, ali incluídos os hospitais? Para responder a esta questão, apoiamo-nos no nosso marco teórico e em experiências de descentralização, como a reforma do hospital da Fundação Santa Casa de Belém, descrita por Cecilio (1993), e de dois casos internacionais descritos por Smith et al. (s/ data): os modelos organizacionais do John Hopkins Hospital (E.U.A.) e do Sunnybrook Medical Centre (Canadá).

Um dos pontos de partida desse modelo estaria representado pela estruturação dos estabelecimentos segundo desenhos organizacionais articulados por unidades autônomas ou semi-autônomas de trabalho definidas por conjuntos de produtos integrados. As duas experiências internacionais referidas se organizam em termos de linhas de produtos ou de programas, segundo critérios convencionados ou negociados. Esta organização por produtos tende a se superpor, em alguma medida, às especialidades médicas, configurando um desenho onde os critérios funcional e por produto se misturam.

O essencial da proposta vem a ser a descentralização efetiva do poder para essas unidades de trabalho, incluindo o planejamento e a responsabilidade financeira, e a forma particular de gerenciamento político das mesmas, caracterizada por uma equipe de gestão formada por um diretor de enfermagem, um administrador e um diretor geral da unidade clínica, sob a direção deste último, em geral um médico. Esta equipe que opera por consenso implica a superação da tradicional divisão funcional da organização sanitária em torno das três categorias básicas de atores sanitários e configura um elemento decisivo na busca de uma coordenação comunicativa intraorganizacional. Como sustenta Smith: "Historically, by structuring along functional lines, health services organizations have emphasized the divisiveness that exits among the various health professions. Sometimes, the result has been a fragmented approach to patient services, which may negatively affect patient outcomes. Much discussions in health services today emphasizes the need for a team approach where all health professionals work together to providea more continuous and enhanced quality of patient care... Explicit in the design of the SMC model is the need for a structure which enhances multidisciplinary and participatory approaches to the provision of patient care services. Achieving this objective is partiality realized through the multidisciplinary management team of physician, nurse, and administrator that manages each unit".

A integração horizontal das unidades de trabalho poderia ser estabelecida por um colegiado geral de gestão ou por uma dinâmica de reunião periódica envolvendo os diretores das unidades. Formas colegiadas mais amplas poderiam ser preconizadas para operar abaixo da equipe de gestão, complementando a estratégia de implementação de formas de comunicação/ coordenação. Dizemos formas colegiadas e não necessariamente colegiados permanentes de gestão, cuja possibilidade de funcionamento efetivo dependeria em muito da cultura específica e de não inviabilizar a perspectiva de atuação ágil da equipe básica de gestão. Acreditamos, por outro lado, que respeitar em boa 
medida o predomínio efetivo dos médicos na representação política dos estabelecimentos sanitários é mais condizente com a cultura institucional do que fórmulas populistas que podem afastar ainda mais tais profissionais da difícil perspectiva de engajá-los na sistemática de gestão.

Uma característica importante destas experiências internacionais é a normalização dos papéis gerenciais dos três membros da equipe, visando a uma redução de variedade entre as unidades. Em geral, o papel da diretora de enfermagem é administrar e supervisionar o staff de enfermagem e participar como parte da equipe de gestão de cada unidade. O administrador daria suporte administrativo ao diretor de unidade e garantiria a implementação dos planos e objetivos da unidade, lidando prioritariamente com questões orçamentárias e financeiras.

Um aspecto importante ligado à busca de uma maior coordenação intra e interunidades estaria representado pela introdução da lógica do planejamento por problemas e operações articuladores. A figura dos responsáveis por operações brindaria o elemento de matricialidade à estrutura organizacional pertinente. Uma relação comunicativa expedita e permanente entre os representantes do gerenciamento por operações e os níveis decisórios da estrutura mais permanente é uma condição básica para que o planejamento estratégico não seja una mera ficção e sim uma arma de desenvolvimento institucional ou de mudança.

O tipo de estratégia globalista de desenvolvimento organizacional preconizado à luz do triângulo ferro matusiano é necessário e deve ser adaptado ao contexto sanitário. Garantir a prestação de contas ou a responsabilização, uma gerência criativa que implique o planejamento por problemas e uma racionalização da tomada de decisão em geral são imperativos de construção simultâneos. Porém, como "tudo está em tudo" (parafraseando Bartoli), o ponto de entrada é discutível. O importante é deslanchar um processo desde um ponto determinado, procurando uma abordagem de mudança global.

Como aspectos dignos de ressaltar, devemos citar a necessidade de viabilizar de maneira estável a lógica da problematização a partir de uma metodologia adaptada e simplificada de planejamento situacional e a obrigatoriedade de uma estratégia de treinamento permanente e informal que possibilite a incorporação das práticas de planejamento pelo maior número possível de sujeitos. Dada a particularidade das organizações sanitárias, não se jus- tificam (à luz de Mitzberg) a separação e a hipertrofia de um nível supra-estrutural de planejamento. Teríamos que relativizar o chamamento matusiano para a introdução de sistemas de direção em prol de um entendimento que privilegie a maior incorporação possível de práticas de gestão pelo maior número de atores possível.

Como alguns consultores de gestão e especialistas sanitários recomendam métodos de qualidade total aplicados a saúde e como constatamos não existirem diferenças significativas de lógica entre o instrumental pertinente à qualidade total e à metodologia do PES (vide Contraponto entre o TQC e o PES realizado pelo autor, 1995a), a "não ser" uma maior adequação do PES a situações mal estruturadas de natureza mais política (o que não é pouca coisa), um estímulo no sentido da utilização daqueles deve ser registrado. Se se pensa que esse material de qualidade total é mais adequado culturalmente ao nosso campo, que se aplique de maneira coerente. Como al gumas publicações assim o atestam, por exemplo o livro Melhorando a Qualidade dos Serviços Médicos, Hospitalares e de Saúde de Berwick et al. (I995), a qualidade total também enfrenta em sua aplicação o problema sistemático de envolver os médicos na lógica de uma gestão problematizadora. Este é um problema geral que engloba quaisquer metodologias e se constitui em um desafio cultural básico. Tudo indica que uma boa remuneração geral dos profissionais e um mínimo de estabilidade dos dirigentes são condições importantes para a viabilidade de operação e de permanência de uma proposta de gestão problematizadora que aponte para a mudança. De qualquer modo, o fundamental é a incorporação de um certo nível de metodologia que oriente a gestão segundo a ótica de enfrentar problemas.

A busca de uma certa constância de propósito (parafraseando Deming) depende de um engajamento geral dos médicos. Isto nos leva a considerar a necessidade de não violentar princípios culturais arraigados como o da criatividade no trabalho médico e o derivado da nãopadronização rígida de procedimentos. Não atacar a cultura dos médicos de maneira desnecessária é um conselho a ser dado a consultores de gestão sanitária que se entusiasmam facilmente com os "fluxogramas de processo de trabalho médico" e com uma perspectiva de controle político-econômico do trabalho desses profissionais que reincide em variantes tayloristas. Se se argúi no senti do de que a reconstituição dos processos envolvidos nos produtos do trabalho médico visa a apontar proble- 
mas de descoordenação entre setores e/ ou categorias, que ao nosso ver são problemas bastante recorrentes, uma simples sessão de problematização na linha do PES ou de um método derivado mais simples pode trazer à tona com facilidade essa situação a nível de sua descrição e de suas causas. Não é necessário ressuscitar o espírito da normatização de tempos e movimentos, da organização e métodos, para lidar com problemas que implicam uma comunicação problematizadora representativa dos setores envolvidos, como eixo básico de intervenção. Neste sentido, questionamos más aplicações da qualidade total que deixam transparecer um estilo excessivamente prescritivo ou controlador.

Uma outra questão que deve ser destacada como parte do esforço de responsabilização de uma estratégia de reforma organizacional é a da prestação de contas. Como apontamos anteriormente, não haveria indicadores ou critérios absolutos de avaliação ou de controle de qualidade, a não ser aqueles estabelecidos consensualmente pelos sujeitos-objetos da avaliação. Isto adquire uma vigência particular em um meio onde a imprecisão de produtos e resultados, de critérios de eficácia, é bastante nítida. A existência, em geral, de vários critérios de acordo com a posição dos vários atores organizacionais, de suas racional idades diferenciadas, obriga a uma negociação. Longe do estilo da hipersaturação de controles, de que fala criticamente a Reengenharia, sugere-se um tipo de controle baseado em poucos e expressivos indicadores consensuais.

Propõe-se a idéia de pelo menos um indicador de cada produto de unidade de trabalho, mais algum(ns) indicador(es) representativo(s) da unidade em geral. Por exemplo, a unidade de toco-ginecologia compreenderia alguns produtos básicos como partos normais, cesarianas, cirurgias obstétricas, internações ginecológicas etc. Para cada produto, poderia ser estabelecido um indicador. Fica claro que a definição dos indicadores é inseparável da referida declaração da missão. A experiência de consultoria do grupo de planejamento do Departamento de Medicina Preventiva da Faculdade de Medicina da Unicamp sugere a criação de indicadores não clássicos capazes de avaliar a comunicação lateral, como, por exemplo, percentagem de cirurgias não realizadas por falta de roupas ou pela não-real ização de exames laboratoriais, a percentagem de exames realizados em relação aos solicitados em determinado período de tempo etc. Estes indicadores são extremamente interessantes. Por fim, é importante salientar a necessidade de prestar atenção aos indicadores específicos do plano por operações, que podem ou não coincidir com os indicadores gerais de unidades de trabalho.

Três tipos de jornadas podem ser organizadas enquanto lugares amplos de comunicação onde a missão, os indicadores de controle e o plano a partir de problemas seriam processados: jornadas de missão, voltadas para o esclarecimento dos produtos de cada unidade e de suas formas de controle; jornadas de problematização internas a cada unidade visando ao levantamento e processamento de problemas internos; e jornadas de problematização coordenadas, incluindo vários setores, com a finalidade de problematizar situações que implicam a integração.

A análise das experiências internacionais referidas sugere que o fato de descentralizar a responsabilidade financeira para as unidades de trabalho não implica necessariamente atingir o objetivo da redução de custos e que incentivos financeiros adicionais podem tornarse necessários tendo em vista esse fim, como a norma de permitir que o dinheiro economizado seja livremente utilizado para outras finalidades (de desenvolvimento) pelas unidades.

A necessidade de uma autonomia financeira de gestão está quase implícita em um modelo descentralizado. Dada a configuração de nossa administração pública, cercada de controles burocráticos e fiscais, recomendamos prestar particular atenção à figura dos contratos de gestão enquanto formas jurídicas de gerenciamento que, baseadas em uma negociação dos recursos em função de metas e objetivos terminais, permitem uma autonomia financeira e administrativa e um contexto de negociação ampla de compromissos e de formas de controle, estas últimas subordinadas à busca da efetividade.

Por fim, a necessidade de um processo de racionalização da agenda dos dirigentes pode demandar a existência de uma equipe de assessoria da equipe de gestão, que se responsabilize pela organização dessa agenda filtrando os problemas que nela deságuam, restringindo-a a problemas de alto valor e bem processados. Esta equipe de assessoria ou unidade de processamento técnico-político assumiria a responsabilidade pelo planejamento estratégico das unidades, divindo responsabilidades mais típicas do planejamento e da administração com o administrador, este último mais voltado para a programação orçamentária e para a administração normativa.

Como se vê, o grosso da problemática de gestão destas organizações se resume no obje- 
tivo de criar formas de coordenação que operem como formas de tradução específica da proposta da compactação de processos (freios à divisão funcional corporativa e formas de articulação horizontal) e no desenvolvimento de uma lógica comunicacional que, ancorada na figura da problematização, implique uma racionalização do processo de tomada de decisão, aqui incluída a participação ampla e a negociação de interesses.

\section{Cultura e mudança}

Motta (I991) define cultura como o conjunto de idéias, crenças, conhecimentos, costumes, hábitos, aptidões, valores, símbolos e ritos que caracterizam a organização. Esta definição é assumida por esse autor como imprecisa e generalizante, ressaltando que apenas os valores, hábitos e comportamentos resultantes de uma experiência coletiva e compartilhados pelos membros da organização comporiam a cultura. Citando Kanter, Motta destaca que toda história de mudança tem uma pré-história, isto é, condições organizacionais próprias, que favorecem a identificação de problemas e o surgimento de propostas para solucioná-los. O autor refere assim que a mudança exige condições de cultura organizacional e que ela, antes de ser um processo técnico, consiste essencialmente em um processo cultural de alterar valores. Acrescenta que os indivíduos precisam de tempo para compreender, adquirir e praticar novas habilidades, bem como para se adaptar às novas condições de trabalho impostas pela mudança.

Dada a pouca especificidade desta conceituação de cultura, procuraremos circunscrever melhor os eixos básicos da mesma, escorandonos para tal em uma análise das representações de cultura de alguns especialistas feita por Cudicio (1992), incluindo entre aqueles o prof. Maurice Thévenet, autor de l'Audit de la Culture d'Entreprise, o qual foi entrevistado pela autora.

Thévenet aponta que a cultura de uma empresa representa um conjunto de evidências compartilhadas na organização ou o conjunto "das regras do jogo" informais que seriam vivenciadas pelas pessoas dentro da mesma. Ele afirma que o que resulta muito revelador da cultura é o sistema de remuneração, o controle de gestão, o sistema de avaliação dos rendimentos individuais: o verdadeiro sistema de avaliação dos rendimentos individuais e não necessariamente o formal. Este aspecto tem a ver com a concepção da pessoa humana vigen- te em uma empresa, com um conjunto de hipóteses que concernem aos direitos e deveres das pessoas. Neste sentido, Thévenet acentua a importância das regras de responsabilidade matusiana.

A este aspecto básico da dimensão humana Thévenet acrescenta mais dois elementos nucleares da cultura: a percepção do ofício e o tipo de relação com o entorno. A percepção do ofício estaria ligada a como as pessoas vivenciam o oficio, à percepção do mesmo como tendo um papel social específico ou puramente egocêntrico; ao valor atribuído aos produtos do ofício enquanto objetos vividos como positivos e de grande valor ou como objetos negativos e de fraco valor; ao conhecimento da identidade do ofício; à importância concedida à capacitação etc. A relação com o entorno se refere a duas possibilidades extremas: um entorno ameaçador e um entorno vivenciado como ecológico ou repleto de oportunidades. Estas duas percepções implicariam valorações diferentes no nível da organização. Um ambiente ecológico leva a valorar tudo aquilo que possa criar novos recursos, tudo aquilo que vá no sentido de uma ótima adaptação ao entorno. Quando o ambiente é percebido como uma selva perigosa, são valoradas as condutas que apontam à proteção das aquisições, a vencer na concorrência; neste caso, a relação é apresentada como uma luta, a qual aparece na comunicação interna e externa da empresa. É importante entender aqui que o tipo de relação com o entorno se expressa no tipo de organização interna e nas prioridades definidas nas decisões institucionais. O sistema de poder também seria afetado pela percepção do entorno. A referida autora cita a este respeito que, em um entorno onde a comunicação é um dos valores centrais, os comunicadores da empresa concentram um importante poder formal e informal que se insere como um traço dominante da cultura. Em outros casos, prevalece o poder ligado à profissão, por exemplo, o "poder dos engenheiros".

Outro especialista entrevistado por Cudicio adiciona novas dimensões do conceito de cultura: "a razão de ser real da empresa é parte de sua cultura, também o management... se este é autoritário ou participativo o clima cultural se ressente de imediato... mas também se deve integrar à cultura a qualidade e a organização da comunicação"(trad. nossa). Este especialista refere ainda que a motivação do pessoal é sumamente necessária, na medida em que nas organizações de cultura forte as pessoas têm a sensação de compartilhar algo e de pertencer a alguma coisa importante. Esta sensação de 
compartilhar coletivo estaria na base da formação de uma cultura e seria simultaneamente um dado cultural.

Este especialista salienta que haveria determinados eixos de "valores de supervivência" capazes de fazer transparecer uma cultura. A forma de valorização do dinheiro faria parte de um primeiro eixo, assim como a ecologia ou o respeito pelo ambiente. Este eixo expressaria em geral a vivência particular dos benefícios implícitos na missão. Um segundo eixo estaria representado por "uma determinada ordem e determinadas estruturas concernentes ao poder compartilhado". Estruturas ligeiras e flexíveis que permitissem a todos uma contribuição ótima seriam ideais, já que o excesso de estrutura afoga a iniciativa. Um terceiro eixo apontado corresponderia ao tipo de equilíbrio existente entre os três pólos de uma empresa: clientes, patrões e trabalhadores. A questão a ser investigada aqui é a seguinte: sobre que critérios vão se equilibrar esses pólos? Trata-se de um contrato social verdadeiro ou eventualmente de uma simples relação de força entre patrões e empregados, que exclui os clientes? Outra forma geral de colocar a mesma questão seria: Como se equilibram os imperativos econômicos (lucro) com os imperativos sociais, éticos e morais? O último eixo, não desenvolvido, seria o equilíbrio dos cálculos financeiros.

É importante frisar que nesta última visão o sentimento de pertença a um coletivo adquire um realce particular, assim como o papel da comunicação na estruturação de uma cultura dinâmica e na gênese de uma relação contratual onde o consenso é tido como fator de sobrevivência.

Uma das últimas representações exploradas por Cudicio diz respeito ao papel que os quadros diretivos teriam na transmissão ao resto da organização de valores, diretrizes e projetos. Corresponderia ao estilo de personalidade do dirigente em sua relação com a capacidade de comunicar, com a competência comunicativa, que definiria as possibilidades de agregação em torno de determinados objetivos. Já que a transmissão de valores depende muito do estilo dos quadros diretivos, pode-se considerar que a possibilidade de uma dada cultura, especialmente de uma cultura forte, depende de capacidades comunicativas individuais de executivos e dirigentes, sendo que estas últimas seriam passíveis de treinamento. Nesta acepção, a comunicação é vista como o prolongamento necessário da cultura, como seu meio de constituição e dado intrínseco: “el aspecto de la comunicación es la prolongación indispensable a toda definición de cultura o de filosofia de empresa a nível de direcciones generales para que estas ideas impregnen el conjunto del personal".

Bartoli, na obra que aqui utilizamos, aponta para uma relação dialética entre cultura e comunicação, pois, se de um lado reconhece que a comunicação é a base de constituição da cultura, de um outro, assume que a comunicação pressupõe um contexto cultural comum, definindo os elementos da cultura que são particularmente úteis na possibilitação de uma comunicação eficaz:

- Um conhecimento comum da empresa (resultado de uma política de informação);

- uma visão clara dos problemas a resolver;

- um savoir-faire comum no tocante aos métodos de trabalho;

- bases de uma linguagem comum.

Em Comunicação e Gestão Organizacional por Compromissos (Rivera, 1995b), nós assumimos uma aproximação entre o conceito de cultura organizacional e o conceito habermasiano de mundo da vida organizacional. As três dimensões do mundo da vida organizacional seriam: a cultura, representada pelo saber comum da organização, incluindo o savoir-faire e a razão de ser real da mesma; a sociedade, representada pelas formas normativas de integração social, onde podemos incluir o estilo de management, a qualidade da comunicação, o grau de agregação intersubjetiva definido pelo sentimento de pertença à coletividade organizacional e pelos níveis de equilíbrio atingidos pelos atores bási cos da organização na relação de seus interesses; e a personalidade, representada pelas capacidades comunicativas e de socialização da liderança e dos liderados.

Nesse trabalho, ainda, afirmamos que a dimensão cultural senso-lato expressa um conjunto de regras fáticas que subordinariam ou condicionariam as regras (formais) de direcionalidade, de governabilidade e de responsabilidade do modelo matusiano ou que corresponderiam a seu lado real. Poderíamos dizer que nós damos um viés culturalista às regras organizacionais daquele modelo e destacamos a influência da comunicação.

É necessário recordar ainda que Habermas tem aquela visão dialética da cultura e do agir comunicativo implícita acima. Ele sustenta que o mundo da vida é a sede do agir comunicativo, na medida em que toda comunicação enquanto forma de relação com o mundo está baseada naquela pré-compreensão definida pela tradição ou no celeiro cultural e de evidências normativas e subjetivas, o que corresponde ao mundo da vida dos atores. Diferentemente de uma hermenêutica dogmática, Ha- 
bermas, porém, defende a idéia de que não estamos completamente pré-determinados pela tradição, mas que podemos reciclar permanentemente fragmentos de mundo da vida tornados disfuncionais, graças à dimensão discursiva do agir comunicativo. Mais do que podemos, devemos.

Melhor definido o estofo da cultura, procede abordar a questão da mudança cultural no plano geral. Há quase que um consenso de que a cultura não é manipulável e de que custa transformá-la, a não ser através de um processo mais ou menos lento. Sustenta-se que antes de querer transformá-la de maneira voluntarista é necessário prestar-Ihe ouvidos para ver em que medida pode ajudar-nos a mudar. Afinal, é possível transformar a cultura? Como?

Thévenet, na obra de Cudicio que utilizamos, sustenta que : "é possível atuar sobre a cultura e não só é possível, mas permanentemente se atua sobre a cultura da empresa. Uma cultura de empresa é algo que evolui, não está coagulado. Entretanto, quando algo não está coagulado, isto pode levar a crer que é possível agir sobre aquilo no sentido que se queira, o qual não é verdadeiro. Não porque a cultura não esteja coagulada, é possível definir a que estado B irá se transferir esta cultura definida em um estado A: a cultura é algo que não se manipula. Existe uma evolução permanente da cultura que se constrói seguindo suas adaptações a situações novas, para as quais não há uma solução acabada, portanto há de ser criada". (trad. nossa)

Thévenet sustenta, assim, que o processo de mudança cultural, embora possível, segue um rumo indeterminado. Em outra passagem, insinua que um determinado projeto de empresa de caráter mudancista pode impactar ou alterar afirmativamente o formato organizacional e cultural. Chama a atenção para o surgimento de uma sorte de compromisso entre a cultura resistente e o projeto de reforma: “Nociones como calidad se trivializan, pero consecutivamente a la confrontación entre lo que quieren hacer consultores y directivos y la realidad de la cultura de la organización se llega a una espécie de compromiso del cual probablemente quede algo... habrá habido cambio. Resta saber si valió la pena, pero eso es otra cuestión".

A chave para a mudança, implícita na expressão "quanto mais igual, mais muda", consiste, para esse autor, em explorar traços da cultura que podem ser pertinentes ao projeto de mudança, ao enfrentamento de determinados problemas: "dicho de otra forma, el proceso de cambio debe más bién tratar de reforzar lo que existe de pertinente respecto de los pro- blemas concretos existentes, en lugar de querer insuflar otros valores sabiendo que no se sabe hacerlo". Thévenet dá o exemplo da auditoria de um banco, na qual ficou em evidência um traço que dominava a cultura, relativo a como as pessoas percebiam sua atividade. Esta era, acima de tudo, percebida como baseada na relação com a clientela. Thévenet argüiu, perante a direção, que esse traço pode ser considerado um ponto forte, pois os bancos adquirem suas margens de lucro e garantem seu desenvolvimento na relação com a clientela. Mas também esse traço pode ser considerado um ponto fraco, acrescentou o autor, já que em algumas situações apareceu que a relação com o cliente era mais forte que a qualidade do serviço. Concretamente, se o banco comete um erro, o responsável tende a minimizá-lo, al egando que conhece o cliente e que consertará o erro tel efonando para ele mais tarde. Este traço de cultura é um ponto fraco, pois a relação do cliente com o seu banco muda no contexto atual, em face da concorrência ampliada da Europa. Assim, o autor afirma: “Por lo tanto todo el trabajo consiste en explotar lo que funciona bien y debilitarlo planteando cuestiones concernientes a los problemas que atañen a un banco, la evolución del comportamiento de los consumidores. Esa es la lógica del cambio,y no decir piensen calidad de servicio y no relación con el cliente".

A lógica da intervenção da auditoria de cultura consiste, para aquele autor, em interrogarse participativamente sobre o funcionamento de uma organização. Esta interrogação visa a nomear os traços culturais e eventuais problemas, de maneira não culpabilizante. As coisas nomeadas são, então, confrontadas com os dois problemas básicos de uma organização: a interação constante com o entorno e a manutenção da coesão interna. Esta é, segundo Thévenet, a essência do trabalho cultural. Fazer o diagnóstico cultural e confrontá-lo com as duas questões básicas aludidas. Deduzimos que deste confronto poderão surgir definições que apontem para a correção de comportamentos ou de traços culturais inadequados, que seriam aqueles que não responderiam às exigências colocadas pelos problemas básicos. Esta lógica de "exploração do que é" constituiria um processo amplo de discussão de formas de readaptação da cultura existente, que evitaria os problemas de desestabilização e de incoerência que podem advir da pretensão de impor de início o modelo de um novo projeto de empresa.

Este princípio do "quanto mais igual, mais muda" encontra na nossa proposta de modelo 
gerencial uma expressão: uma das questões básicas do enfoque de gestão das organizações profissionais de saúde nos parece ser, junto com autores como Dussault (1992), preservar o princípio da autonomia profissional, especialmente dos médicos, debilitando-o, simultaneamente, ao apontar dois problemas básicos que deveriam ser enfrentados e que resultam de uma autonomia exagerada, quais sejam, a necessidade de responsabilização e a necessidade de coordenação dos membros da equipe de saúde e dos vários setores. Não se trata aqui de propugnar pelo fim da autonomia, mas de encontrar saídas para problemas eventualmente derivados, resgatando aquele princípio e aprimorando-o no sentido de corrigir os desequilíbrios imanentes, isto em um sentido participativo ou de não-exclusão.

Conclusivamente, a questão da mudança em geral implica a necessidade de saber apoiar a mesma em determinados traços culturais que lhe podem ser positivos e assumir em relação àqueles uma postura crítica necessária que possa redundar na sua reciclagem ou aperfeiçoamento.

Bartoli, por outro lado, também adota o ponto de vista de que um projeto organizacional pode impactar a cultura e promover sua transformação: “...la cultura não es maleable fisicamente. Sólo evoluciona por efecto indirecto, vinculado al desarrollo de estrategias, comportamientos, acciones estructurales y otras facetas de la organización". Esta colocação evoca a idéia de uma sorte de compromisso entre o projeto e a cultura em que o saldo é algum tipo de mudança pouco determinada.

A autora concede especial importância a um plano de comunicação/ organização que impacte a cultura. Coerente com a sua visão globalista de atuação, ela sugere reajustes organizacionais no sentido de estruturas matriciais e de uma maior coordenação horizontal, novas formas de organização do trabalho, por exemplo, o enriquecimento de tarefas, formas de racionalização de procedimentos e propostas no sentido de uma redução do isolamento das unidades e de uma maior possibilidade orgânica de consertação ou negociação entre os vários níveis organizacionais. Está consciente de que a abertura de canais de comunicação através de dispositivos e lugares de comunicação orgânicos é a melhor forma de reciclar a cultura, ao possibilitar uma redefinição da missão e dos projetos de trabalho e ao gerar um senso amplo de participação e de pertença social.

Nesta linha geral de pensamento, concluímos que entre a cultura e um projeto de refor- ma dominado pela busca do desbloqueio comunicativo e da descentralização racional se estabelece uma dinâmica interativa, que se caracteriza pela possibilidade geral de uma mudança inestruturada, onde os fatores estabilidade da liderança e a vontade persistente de impulsionar um processo demorado se constituem em requisitos indispensáveis. Desta maneira, as diretrizes de estratégia que constam do item anterior podem, no seu conjunto, ajudar a mudar as estruturas de uma cultura conservadora que mesmo assim muda como necessidade até de sobrevivência. No entanto, esta mudança de cultura virtual deve ser "pensada" a partir de elementos já inscritos na cultura "anterior", que podem potencializar e garantir a mudança. Mudar de dentro de uma cultura estabelecida ou mudar a cultura a partir da própria cultura, em um processo nitidamente comunicativo, parece ser a fórmula contraditória que resume o potencial de transformação organizacional.

De qualquer maneira, uma postura distanciada da cultura tradicional é possível e necessária. Se acreditarmos no potencial do agir comunicativo habermasiano, a evolução cultural deve ser assumida como uma realidade. O contrário significaria a impossibilidade de toda mudança.

\section{Comentários finais}

O PES de Matus é particularmente útil no que diz respeito aos aportes de sua Teoria Macroorganizacional ao desenho de modelos de gestão comunicativos. Nosso objetivo foi extrair daquela elementos que ajudam a pensar uma reforma administrativa que aponte para a descentralização e a racionalidade de gestão. Descentralização, responsabilização e planejamento criativo se articulam como uma necessidade interna ao modelo do autor.

A não-focalização específica da racionalidade das organizações sanitárias pelo PES obriga, no entanto, a lançar mão de referenciais específicos, como a tipologia organizacional de Mitzberg e todo o material de autores citados neste trabalho, que discutem a especificidade de seus processos tecnológicos e políticos e suas implicações sobre a gestão necessária.

A reconstrução que fazemos de Matus implica a aplicação da teoria do agir comunicativo habermasiana, particularmente trabalhada em conexão com trabal hos mais estritamente gerenciais de autores que nos permitem articular aquela teoria geral com o campo mais pragmático da gerência. 
Surge a necessidade, ainda, de uma revisão de experiências de gestão descentralizada de estabelecimentos sanitários de maneira a captar novos e específicos elementos que a prática da gestão real pode acrescentar decisivamente à reflexão teórica, condicionando-a.

A necessidade de trabalhar com um referencial sobre cultura viria complementar as metodologias de gerência a partir de problemas, incluindo o modelo matusiano. Os dados apresentados aqui, bastante incipientes, terão que ser complementados mais adiante. Esses dados, porém, sugerem um roteiro mínimo de informação capaz de orientar uma auditoria de cultura e uma abordagem problematizadora da mesma. Sentimo-nos fortemente inclinados a pensar que nossa investigação deveria se desdobrar nesse sentido específico no futuro, pela intuição de que, sem essa preocupação, a possibilidade de reformas a partir de metodologiais racionais de gestão fica bastante comprometida. E esta preocupação se insere com particular exclusividade no campo que vimos assumindo como o nosso objeto: a Comunicação e a Gerência.

\section{Referências}

BARTOLI, A., 1992. Comunicación y Organización. La Organización Comunicante y la Comunicación Organizada. Buenos Aires: Ed. Paidós.

BERWICK, D. M.; GODFREY, A. B. \& ROESSNER, A. B., 1995. Melhorando a Qualidade dos Serviços Médicos, Hospitalarese da Saúde. São Paulo: Makron Books.

CECILIO, L. C. O., 1993. Inventando a Mudança na Administração Pública: Reconstituição e Análise deTrês Experiências de Saúde. Tese de Doutorado, Campinas: Faculdade de Medicina, Universidade Estadual de Campinas.

COVEY, S. R., 1994. Liderança Baseada em Princípios. Rio de Janeiro: Ed. Campus.

CUDICIO, C., 1992. La Programación Neurolingüística, la Cultura dela Organización y su Dimensión Criativa. Buenos Aires: Granica Ediciones.

DUSSAULT, G. A., 1992. Gestão dos serviços de saúde. Características e exigências. Revista de Administração Pública, 26:8-19.

FLORES, C. F., 1989. Inventando la Empresa del Siglo XXI. Santiago de Chile: Hachette.

HAMMER, M. \& CHAMPY, J., 1994. Reengenharia. Revolucionando a Empresa em Função dos Clientes, da Concorrência e das Grandes Mudanças da Gerência. Rio de Janeiro: Ed. Campus.

LEMOS, S. M., 1994. Definição e implementação de objetivos nas organizações públicas de saúde. Revista deAdministração Pública, 28:38-64.
MATUS, C., 1994a. Sobrela Teoría de las Macroorganizaciones. Santafé de Bogotá: Fondo Editorial Altadir.

MATUS, C., 1994b. Guía Teórico del PES. Caracas: Fundación Altadir. (mimeo.)

MATUS, C., 1994c. El Método PES, Reingeniería Pública y la Teoría de las Conversaciones: Trabas y Problemas. Colección Ciencias y Técnicas de Gobierno $\mathrm{n}$ ㅇ 2, Santafé de Bogotá: Fondo Editorial Altadir.

MATUS, C., 1994d. Manual Altadir de Monitoramiento. Caracas: Fundación Altadir. (mimeo.)

MOTTA, P. R., 1991. Gestão Contemporânea. A Ciência e a Arte de Ser Dirigente. Rio de Janeiro: Ed. Record.

RIVERA, F. J. U, 1995a. Por um Contraponto TeóricoMetodológi co entreo PES eo TQC na Saúde Pública. Série Estudos de Saúde Coletiva 10, Rio de Janeiro: Instituto de Medicina Social.

RIVERA, F. J. U., 1995b. Comunicação e Gestão Organizacional por Compromissos. Rio de Janeiro: Escola Nacional de Saúde Pública. (mimeo.)

SMITH, T.; LENTT, P.; ELLIS, P. \& FRIED, B., (sem data). Decentralized Hospital Management: Rationale, Potencial, and Two-Case Examples. Health Matrix, 7:11-17. 